\title{
Effects of rumen-protected choline on the inflammatory and metabolic status and health of dairy cows during the transition period
}

\author{
J. M. Bollatti, ${ }^{1}$ M. G. Zenobi, ${ }^{1}$ N. A. Artusso, ${ }^{1}$ A. M. Lopez, ${ }^{1}$ C. D. Nelson, ${ }^{1} \odot$ B. A. Barton, ${ }^{2}$ C. R. Staples, ${ }^{1} \odot$ \\ and J. E. P. Santos ${ }^{1 *}$ (i) \\ ${ }^{1}$ Department of Animal Sciences, University of Florida, Gainesville 32611 \\ ${ }^{2}$ Balchem Corp., New Hampton, NY 10958
}

\begin{abstract}
The objectives of this study were to evaluate the effects of rumen-protected choline (RPC) supplementation from $21 \mathrm{~d}$ pre- to $21 \mathrm{~d}$ postpartum on markers of metabolic status and inflammatory response, concentrations of liposoluble vitamins, and plasma total $\mathrm{Ca}$ in parous Holstein cows. The hypotheses were that supplementing RPC during the transition period would reduce hepatic triacylglycerol accumulation postpartum and attenuate markers of inflammatory response following parturition, and collectively, such responses were expected to benefit health of dairy cows. Parous cows at $241 \mathrm{~d}$ of gestation were blocked by parity group and 305-d milk yield, and within block, they were assigned randomly to receive either $0 \mathrm{~g} / \mathrm{d}$ [no choline in transition $(\mathrm{NT}), \mathrm{n}=55]$ or $12.9 \mathrm{~g} / \mathrm{d}$ choline ion [choline in transition $(\mathrm{CT}), \mathrm{n}=58$ ] from $21 \mathrm{~d}$ pre- to 21 postpartum. The RPC product was individually topdressed onto the total mixed ration once daily. Prepartum, treatments were supplemented (mean \pm standard deviation) for the last $18.8 \pm 5.7$ and $19.2 \pm 5.0 \mathrm{~d}$ of gestation in NT and CT, respectively. Supplementing RPC prepartum did not affect concentrations of plasma metabolites and inflammatory markers during the last 3 wk of gestation. Postpartum, cows fed RPC had greater hepatic concentration of hepatic triacylglycerol $(\mathrm{NT}=$ 3.4 vs. $\mathrm{CT}=4.4 \%$ ) and tended to have increased concentration of $\beta$-hydroxybutyrate $(\mathrm{NT}=0.48$ vs. $\mathrm{CT}=$ $0.53 \mathrm{mM}$ ) in plasma. In spite of the increased hepatic triacylglycerol in cows fed RPC, treatment did not affect the concentrations of the inflammatory marker tumor necrosis factor- $\alpha$ or of the positive acute phase proteins, haptoglobin and fibrinogen. Supplementing choline tended to increase the concentration of plasma
\end{abstract}

Received July 18, 2019.

Accepted September 23, 2019.

*Corresponding author: jepsantos@ufl.edu triacylglycerol by $0.69 \mathrm{mg} / \mathrm{dL}$ in the first $21 \mathrm{~d}$ postpartum and reduced the incidence of subclinical hypocalcemia by 20.9 percentage units compared with NT. Supplementing transition cows with RPC did not affect the concentrations of liposoluble vitamins in the first 7 d postpartum or the incidence of individual diseases or morbidity in early lactation. The inability of supplemental choline to reduce hepatic triacylglycerol might have been a consequence of the increased productive performance without additional dry matter intake.

Key words: choline, dairy cow, fatty liver, transition

\section{INTRODUCTION}

Calving and the onset of lactation increases the risk of diseases in a period in which cows undergo extensive tissue mobilization because of negative nutrient balance. The rapid increase in demands for nutrients to support the accelerated fetal growth and onset of lactation, accompanied by a 30 to $35 \%$ decrease in feed intake during the final week of gestation (Bertics et al., 1992), and insufficient early postpartum intake (Bell, 1995) results in negative nutrient balance, rapid adipose tissue mobilization, and consequently increased ketogenesis and hepatic infiltration of fat (Bobe et al., 2004). Most diseases of dairy cows occur within the first 3 wk of lactation (Ribeiro et al., 2016), and disease results in inflammation that promotes further liver fat accumulation (Bradford et al., 2009). It is thought that the success of the transition period determines, to a large extent, the success of the entire lactation. Therefore, nutritional manipulations that improve metabolism, reduce inflammation, or reduce the risk of disease are expected to benefit productive performance (Drackley, 1999).

Choline, a micronutrient considered to be a quasivitamin (Combs, 2012), is supplemented to dairy cows in part because its lipotropic functions (Erdman et al., 1984). Nevertheless, choline needs to be fed as rumen-protected because it is extensively degraded by microbes in the rumen (Sharma and Erdman, 1988). 
Protecting choline by lipid coating in rumen-protected choline (RPC) products prevents microbial degradation and supplies choline ions for postrumen absorption. Rumen-protected choline has been effective to prevent and alleviate hepatic triacylglycerol infiltration in nonlactating pregnant cows under induced feed restriction (Cooke et al., 2007; Zenobi et al., 2018b) and during early lactation when supplemented to transition cows (Santos and Lima, 2009; Zom et al., 2011; Elek et al., 2013), although response in postpartum cows has been inconsistent (Piepenbrink and Overton, 2003; Zahra et al., 2006; Zenobi et al., 2018a).

It has been proposed that choline might play important roles other than reducing hepatic triacylglycerol accumulation. Zenobi et al. (2018b) suggested that choline might improve integrity of the gastrointestinal mucosa and enhance absorption of nutrients in prepartum cows either helping repair a damaged protective barrier in the intestine or by improving synthesis of lipoproteins. Supplementing choline to feed-restricted cows increased plasma triacylglycerol concentration after a challenge with fatty acids (Zenobi et al., 2018b). Also, feeding $\mathrm{RPC}$ has been reported to increase concentrations of $\alpha$-tocopherol in dairy cows (Pinotti et al., 2003; Sun et al., 2016) possibly because of improved lipid absorption and transport of fat-soluble vitamins across the enterocytes. Interestingly, supplementing RPC to transition cows also increased the concentration of plasma total calcium (tCa) in the first $7 \mathrm{~d}$ postpartum (Zenobi et al., 2018a), thereby resulting in reduced prevalence of subclinical hypocalcemia. Authors suggested possible improved gastrointestinal absorption of $\mathrm{Ca}$, altered vitamin $\mathrm{D}$ availability, or attenuated inflammatory status, all of which were expected to increase plasma Ca.

If choline plays a role in intermediary metabolism, can attenuate inflammation, and improve nutrient absorption, then it is plausible to suggest that it might reduce the risk of periparturient diseases, many of which are of metabolic or inflammatory nature. Recently, Arshad et al. (2020) showed that supplementing diets of transition dairy cows with RPC tended to reduce the incidence of retained fetal membranes and mastitis postpartum.

The hypotheses were that supplementing RPC during the transition period would reduce hepatic triacylglycerol content and markers of inflammatory response following parturition. Collectively, such responses were expected to benefit health of dairy cows. Therefore, the objectives of the experiment were to evaluate the effects of RPC supplementation initiated $21 \mathrm{~d}$ prepartum and continued through early lactation on the metabolic status, markers of inflammatory response, concentrations of liposoluble vitamins, and Ca homeostasis of parous Holstein cows. This paper is a companion to
Bollatti et al. (2020) in which productive responses are reported.

\section{MATERIALS AND METHODS}

The experiment was conducted at the University of Florida Dairy Unit from November 2016 to September 2017. All procedures involving cows in the experiment were carried out according to the University of Florida's Institutional Animal Care and Use Committee.

\section{Cows, Housing, Feeding Management, and Treatments}

At $241 \pm 2.2 \mathrm{~d}$ of gestation (SD; 241 to 251 ), 113 pregnant nonlactating Holstein cows that had completed at least one previous lactation were enrolled in the experiment. Selection criteria included apparently healthy pregnant cows with no history of disease in the $90 \mathrm{~d}$ preceding experiment enrollment. Details of cows, housing, and general management are presented in Bollatti et al. (2020).

Description of the diets, and details of feed ingredients and chemical analyses are presented elsewhere in Bollatti et al. (2020). All cows were fed the same diet individually using feeding gates (Calan gates, American Calan Inc., Northwood, NH) within the pre- and the postpartum periods. Diets pre- and postpartum were formulated to supply adequate amounts of MP and metabolizable methionine (Bollatti et al., 2020). The DCAD of the prepartum diet was (mean \pm SD) -104 $\pm 17 \mathrm{mEq} / \mathrm{kg}$.

The experiment followed a randomized block design with cow as the experimental unit. Weekly cohorts of prepartum cows at $241 \mathrm{~d}$ of gestation were blocked by parity (lactation 1 vs. lactation >1) and 305-d milk yield, and within block, they were assigned randomly to no choline in transition (NT, $\mathrm{n}=55$ ) or supplementation with choline in transition $(\mathbf{C T}, \mathrm{n}=58)$. Cows in NT received $200 \mathrm{~g} / \mathrm{d}$ of ground corn and dried molasses in an 80:20 ratio as top-dress, whereas CT cows were supplemented with a RPC product containing $28.8 \%$ choline chloride to supply a daily dose of $12.9 \mathrm{~g}$ of choline ion (60 g/d ReaShure, Balchem Corp., New Hampton, NY). The RPC product was mixed with ground corn and dried molasses in a 30:56:14 ratio (as-is basis) and top-dressed at $200 \mathrm{~g} / \mathrm{d}$ onto the TMR concurrent with the morning feeding. Supplementation started at d -21 prepartum until 21 d postpartum.

\section{Blood Sampling and Processing}

Blood was collected on the day of experiment enrollment, which was denoted as d -21 , then once weekly 
prepartum, and again on d $0,1,2,3,7,14$, and 21 postpartum by puncture of the coccygeal vessels into evacuated tubes (Vacutainer, Becton Dickinson, Franklin Lakes, NJ) containing lithium heparin. Prepartum samples closest to the expected day prepartum were analyzed $(-14 \pm 4$ and $-7 \pm 4 \mathrm{~d}$ relative to calving). All blood samplings were performed early in the morning before feeding, except for the day of calving in which blood was collected within $2 \mathrm{~h}$ after parturition regardless of the time of the day. Upon collection, tubes were placed on ice and then centrifuged within $30 \mathrm{~min}$ of collection at $1,125 \times \mathrm{g}$ for $15 \mathrm{~min}$ at room temperature, plasma was harvested, and multiple aliquots of 1.5 $\mathrm{mL}$ were frozen at $-30^{\circ} \mathrm{C}$ until analysis.

\section{Blood Assays}

Plasma samples collected on d $-21,-14,-7,0,7$, 14 , and 21 relative to calving were assayed for BHB, fatty acids, glucose, urea N, fibrinogen, and haptoglobin. Triacylglycerol in plasma was assayed on samples collected on d $-21,-14,-7,0,3,7,14$, and 21 relative to calving. Samples collected on d 3, 7, and 14 postpartum were assayed for tumor necrosis factor- $\alpha$ (TNF $\mathbf{\alpha})$. Samples collected on $\mathrm{d} 0,3$, and 7 postpartum were assayed for concentrations of $\alpha$-tocopherol, retinol, $\beta$-carotene, and calcidiol, whereas those collected on $\mathrm{d}$ $0,1,2$, and 3 postpartum were assayed for concentrations of tCa. Plasma samples from cows that received treatments with $\mathrm{Ca}$ or dexamethasone were removed from statistical analyses. All assays followed the initial randomization with blocks, such that samples from each block were analyzed in the same assay. In every assay, 2 plasma samples were included in duplicate at the beginning and again at the end to calculate intraand interassay coefficients of variation $(\mathbf{C V})$.

Plasma concentrations of fatty acids (NEFA-C kit; Wako Diagnostics Inc., Richmond, VA; according to Johnson and Peters, 1993) and BHB (Wako Autokit 3-HB; Wako Diagnostics Inc.) were determined in single and duplicate samples, respectively. Intra- and interassay CV were, respectively, 3.3 and $4.4 \%$ for fatty acids and 11.7 and $10.2 \%$ for BHB. Plasma triacylglycerol concentration was analyzed in duplicates with a commercial kit (Stanbio Triglycerides LiquiColor Procedure No. 2100, Stanbio Laboratory, Boerne, TX), and intra- and interassay CV were 7.4 and $12.4 \%$. A Technicon Autoanalyzer (Technicon Instruments Corp., Chauncey, NY) was used to measure concentrations of plasma glucose (Bran and Luebbe Industrial Method 339-19; Gochman and Schmitz, 1972) and urea N (Bran and Luebbe Industrial Method 339-01; Marsh et al., 1965). The intra- and interassay CV were 7.2 and
$8.7 \%$ for glucose and 3.4 and $13.0 \%$ for plasma urea $\mathrm{N}$, respectively.

Plasma concentrations of haptoglobin were assayed using a colorimetric procedure that measured haptoglobin-methemoglobin complexing by estimating differences in peroxidase activity (Makimura and Suzuki, 1982). Results were expressed as optical density (OD) reading at $450 \mathrm{~nm}$. The OD values were expressed multiplied by 100 for statistical analysis. Samples were analyzed in duplicate and the intra- and interassay CV were 5.6 and $7.2 \%$, respectively. Plasma concentrations of fibrinogen were determined using a fibrinogen determination kit (TriniCLOT Fibrinogen kit no. T1301; Tcoag, Ireland Limited, Ireland) by estimating clotting time using a BBL fibrometer coagulation analyzer (Rankin Biomedical Corp., Holly, MI). Samples were analyzed in duplicate and the intra- and interassay CV were 2.2 and $2.5 \%$, respectively. Plasma concentrations of TNFo were assayed as described by Farney et al. (2011) using bovine-specific antibodies (\#ENPBOTNFABI; ENPBOTNFAI) and bovine-specific recombinant protein (\#ENRBOTNFAI, Thermo Fisher Scientific, Rockford, IL). The intra- and interassay CV were 8.4 and $4.7 \%$, respectively.

Concentrations of $\alpha$-tocopherol, retinol, and $\beta$-carotene were measured by high-performance liquid chromatography (Waters Aquity H-class UPLC, Waters Corporation, Milford, MA) as described by Blanco et al. (2000). Briefly, $200 \mu \mathrm{L}$ of plasma was added to $200 \mu \mathrm{L}$ of ethanol containing $1 \mu \mathrm{g} / \mathrm{mL}$ retinyl-acetate (Sigma-Aldrich, St. Louis, MO) as an internal standard. Samples were vortexed for $10 \mathrm{~s}$, then $1.5 \mathrm{~mL}$ of hexane was added to samples and vortexed for $10 \mathrm{~min}$. The lipid-soluble fraction was separated by centrifugation for $15 \mathrm{~min}$ at $1,000 \times g$ at room temperature. The hexane layer was collected and dried with vacuum centrifuge. The extracts were reconstituted in $200 \mu \mathrm{L}$ of ethanol and filtered through a $0.2-\mu \mathrm{m}$ filter. Samples were assayed in single, and the intra- and interassay CV were, respectively, 2.2 and $8.6 \%$ for $\alpha$-tocopherol, 7.8 and 9.0 for retinol, and 5.0 and $14.9 \%$ for $\beta$-carotene. Calcidiol is the standard vitamin D quantified to determine adequacy because it is the predominant metabolite found in plasma and has a long half-life (Nelson et al., 2016; Rodney et al., 2018). Concentrations of calcidiol were analyzed in single by ELISA (Eagle Bioscience VID31-K01 25-OH vitamin D ELISA assay kit, Eagle Biosciences, Amherst, NH) according to the manufacturer's instructions, except that a custom standard prepared in bovine serum was used in place of the standard provided with the kit, as described Nelson et al. (2016). The intra- and interassay CV were 12.5 and $22.5 \%$, respectively. Plasma concentrations of tCa were 
analyzed using an atomic absorption spectrophotometer (AAnalyst 200, Perkin-Elmer Inc., Waltham, MA) with the flame technique and acetylene gas. The intraand interassay $\mathrm{CV}$ were 0.5 and $1.2 \%$, respectively.

\section{Liver Collection and Measurements}

Liver tissue was sampled on d 7, 14, and 21 postpartum as described by Zenobi et al. (2018a). At each sampling day, approximately $1.0 \mathrm{~g}$ of tissue was collected, rinsed with sterile saline, and then sliced into 3 sections. Samples were transferred into individual cryovials, snap-frozen in liquid $\mathrm{N}$, and stored at $-80^{\circ} \mathrm{C}$ until analysis of concentrations of triacylglycerol. One vial containing at least $300 \mathrm{mg}$ of hepatic tissue was thawed on ice, and the sample transferred to filter paper to dry the surface. A 300-mg sample was homogenized in $3 \mathrm{~mL}$ of saline solution using an Ultra-Turrax T25 homogenizer (Rose Scientific Ltd., Edmonton, AB, Canada). Six milliliters of 1:1 saline:methanol was added to each sample and then split into 3 equal aliquots. One aliquot was used to analyze tissue DM in triplicate. A second aliquot was used to analyze triacylglycerol. The third aliquot was frozen and later analyzed for total DNA content.

Dry matter was determined in triplicate, each sample containing $0.5 \mathrm{~mL}$ dried at $55^{\circ} \mathrm{C}$ for $48 \mathrm{~h}$ in a forced-air oven. A second aliquot was analyzed for concentration of triacylglycerol in triplicate. Lipids were extracted in triplicate using chloroform:methanol 2 to 1 solution (Folch et al., 1957). Each of the 3 extracted samples were assayed for triacylglycerol using a colorimetric method (Foster and Dunn, 1973). The intra- and interassay CV averaged 4.2 and $5.6 \%$, respectively. The third aliquot was assayed for total DNA (Labarca and Paigen, 1980). The intra- and interassay CV averaged 3.3 and $7.8 \%$, respectively.

\section{Characterization and Diagnosis of Health Problems}

Incidence of diseases was evaluated for the first 21 d postpartum. Milk fever was diagnosed based on clinical signs of recumbency that responded to an i.v. administration of a solution containing $10.8 \mathrm{~g}$ of $\mathrm{Ca}$ as Ca borogluconate (Cal-Dex CMPK injection, Agrilabs, St. Joseph, MO) and confirmed based on plasma tCa concentration. A blood sample was collected before therapy and plasma tCa was analyzed and the 3 cows with clinical hypocalcemia had plasma tCa $<1.4 \mathrm{mM}$. Retained fetal membranes was defined as a cow that failed to expel the fetal membranes within $24 \mathrm{~h}$ after parturition.

All cows underwent a complete physical examination on $\mathrm{d} 4,7,10$, and 12 postpartum. In addition, any cow with altered behavior that might indicate disease such as inappetence or a decline in milk yield by more than $15 \%$ relative to the production on the previous day were also examined. Rectal temperature was measured, and fever was considered when greater than $39.5^{\circ} \mathrm{C}$. Cows were palpated transrectally and presence of an enlarged flaccid uterus with fetid watery reddish-brownish discharge was defined as metritis. Metritis concurrent with fever was considered puerperal metritis. Diagnosis of displaced abomasum was performed by percussion and auscultation of the left and right flanks and confirmed during surgical intervention for correction by omentopexy. Immediately before every milking, all cows were examined for signs of clinical mastitis by the herd personnel based on the presence of abnormal milk in one or more quarters. Cows with increased respiratory frequency with increased lung sounds at auscultation and fever were considered to have respiratory disease. Morbidity included the following clinical diseases: milk fever, retained placenta, metritis, displaced abomasum, mastitis, and respiratory disease. Cows with more than one clinical disease were classified as having multiple diseases.

Urine was sampled on d 4, 7, 10, and 12 postpartum, and on any day a cow was suspected of having ketosis. Cows diagnosed as having moderate $(\sim 0.4 \mathrm{~m} M)$ or large ketone concentrations $(>0.8 \mathrm{mM})$ in urine were considered to have hyperketonuria (URS-1K, Teco Diagnostics, Anaheim, CA). Incidence of subclinical hypocalcemia was based on at least 1 sample with plasma tCa $<2.0 \mathrm{~m} M$ (Reinhardt et al., 2011) on d 0 , 1,2 , or 3 postpartum. Daily prevalence of subclinical hypocalcemia was evaluated from 0 to $3 \mathrm{~d}$ postpartum. Hyperketonemia was defined as plasma BHB concentrations $>1.20 \mathrm{~m} M$ on at least one sample collected on d $0,7,14$, and 21 postpartum based on McArt et al. (2011). Incidence of fatty liver was determined based on at least 1 sample of hepatic tissue with triacylglycerol content greater than $5 \%$ of wet tissue (Gaal et al., 1983) on d 7, 14, or 21 postpartum. The prevalence of fatty liver was also evaluated in weekly samples collected from 7 to $21 \mathrm{~d}$ postpartum.

Vaginal discharge was collected at $21 \pm 3 \mathrm{~d}$ postpartum using the Metricheck device (Kiwikit Ltd., Wales, New Zealand) and scored as described by Lima et al. (2013). Cows having a vaginal discharge score $>2$ were classified as having endometritis (Lima et al., 2013).

\section{Statistical Analyses}

The experiment was a randomized block design. Cow was the experimental unit, and both cow and block were considered as random effects in the statistical models. At the time of treatment assignment, prepar- 
tum cows at $241 \mathrm{~d}$ of gestation were blocked by parity group prepartum (lactation 1 vs. lactation $>1$ ), and within parity group, ranked by 305-d milk yield from lowest to highest such that each 4 cows within parity group and level of milk yield were assigned to a block. Within block, cows were assigned randomly to treatments such that 2 cows received NT and 2 cows CT. Data were analyzed separately for the pre- and postpartum periods.

The statistical analyses were performed using the MIXED procedure of SAS version 9.4 (SAS/STAT, SAS Institute Inc., Cary, NC). Normality of residuals and homogeneity of variance were examined for each continuous dependent variable analyzed after fitting the statistical model. Responses that violated the assumptions of normality were subjected to power transformation according to the Box-Cox procedure (Box and Cox, 1964) using PROC TRANSREG in SAS (SAS/ STAT, SAS Institute Inc.). The variables transformed were plasma BHB to the reciprocal $(1 / \mathrm{y})$, and plasma fibrinogen, haptoglobin, $\mathrm{TNF} \alpha$, and $\beta$-carotene to the natural logarithm. The least squares means and respective standard error of the mean for each treatment were back transformed for presentation of the results according to Jørgensen and Pedersen (1998).

All statistical models were pre-planned to address the experimental design implemented and to allow testing the specific hypotheses of the experiment. The models included the fixed effects of treatment (NT vs. $\mathrm{CT}$ ), day of measurement, and the interaction between treatment and day, and the random effects of block and cow nested within treatment. Values measured before treatment administration $(\mathrm{d}-21)$ were used as covariates in the statistical models of data analyzed prepartum. Also, the exact day relative to calving when blood was sampled prepartum was used as covariate to adjust for the deviation in sampling day prepartum. Body weight at enrollment and calf category (singleton male, singleton female, or twin) also were covariates in all statistical models. The Kenward-Roger method was used to calculate the approximate denominator degrees of freedom for the $F$ tests. Also, in all statistical models with repeated measures, the REPEATED statement was used for dependent variables measured over time. Cow was nested within treatment and was the error term for testing the effects of treatment. The covariance structure with the lowest Akaike information criterion was selected for each variable, and spatial power was the covariance structure of choice when intervals between times of sampling were not spaced evenly. When an interaction between treatment and day of measurement resulted in $P<0.10$, then treatment means at different days were partitioned using the SLICE command of SAS (SAS/STAT, SAS Institute Inc.).
Binary data were analyzed by logistic regression with the GLIMMIX procedure of SAS (SAS/STAT, SAS Institute Inc.). The statistical models included the fixed effects of treatment, BW at enrollment, and calf category, and the random effect of block. For binary data with repeated measures within cow such as daily prevalence of subclinical hypocalcemia, fatty liver, and hyperketonemia, then the statistical models also included the fixed effects of day, interaction between treatment and day, and the random effect of cow nested within treatment. Statistical significance was considered at $P \leq 0.05$ and tendency at $0.05<P$ $\leq 0.10$.

\section{RESULTS}

One hundred thirteen parous Holsteins cows were enrolled in the experiment and all of them contributed data for incidence of diseases; however, 14 were removed for reasons detailed in Bollatti et al. (2020) and they did not contribute with data for analyses of blood or liver composition. Therefore, $55 \mathrm{NT}$ and $58 \mathrm{CT}$ were used for disease incidence, whereas $50 \mathrm{NT}$ and $49 \mathrm{CT}$ cows contributed data for blood and liver composition. Descriptive statistics of measures collected at the time of enrollment and at parturition for the 113 cows enrolled in the experiment are presented in Supplemental Table S1 (https://doi.org/10.3168/jds.2019-17294). Data for the 99 cows that contributed with blood and liver data are presented in Bollatti et al. (2020). In the prepartum period, treatments were supplemented (mean $\pm \mathrm{SD}$ ) for the last $18.8 \pm 5.7$ and $18.9 \pm 5.4 \mathrm{~d}$ of gestation in NT and CT cows, respectively.

Details of lactation and reproductive performance are reported in Bollatti et al. (2020). Briefly, supplementing diets with RPC during the transition period did not affect DMI, BCS, BW, or net energy balance prepartum. During the first $21 \mathrm{~d}$ postpartum, feeding $\mathrm{CT}$ increased percentage of milk fat by 0.20 percentage units and yields of fat and ECM by 0.16 and 3.1 $\mathrm{kg} / \mathrm{d}$, respectively, compared with NT. Postpartum DMI did not differ between treatments, but cows fed CT tended to be in a lesser net energy balance than cows fed NT. Treatment did not affect reproduction in dairy cows. Cows fed CT consumed $11.6 \mathrm{~kg}$ of DM per day prepartum, which provided $94 \mathrm{~g} / \mathrm{d}$ of $\mathrm{Cl}$ ions and a resulting DCAD of $-104 \mathrm{mEq} / \mathrm{kg}$ (Bollatti et al., 2020). Supplemental choline as choline chloride resulted in an additional intake of $\mathrm{Cl}$ ions of $4.36 \mathrm{~g} / \mathrm{d}$ (total of $98.36 \mathrm{~g} / \mathrm{d}$ ), which reduced the DCAD of the diet consumed by CT cows to $-112 \mathrm{mEq} / \mathrm{kg}$. Such a small difference is unlikely to affect acid-base balance and mineral metabolism in periparturient cows. 

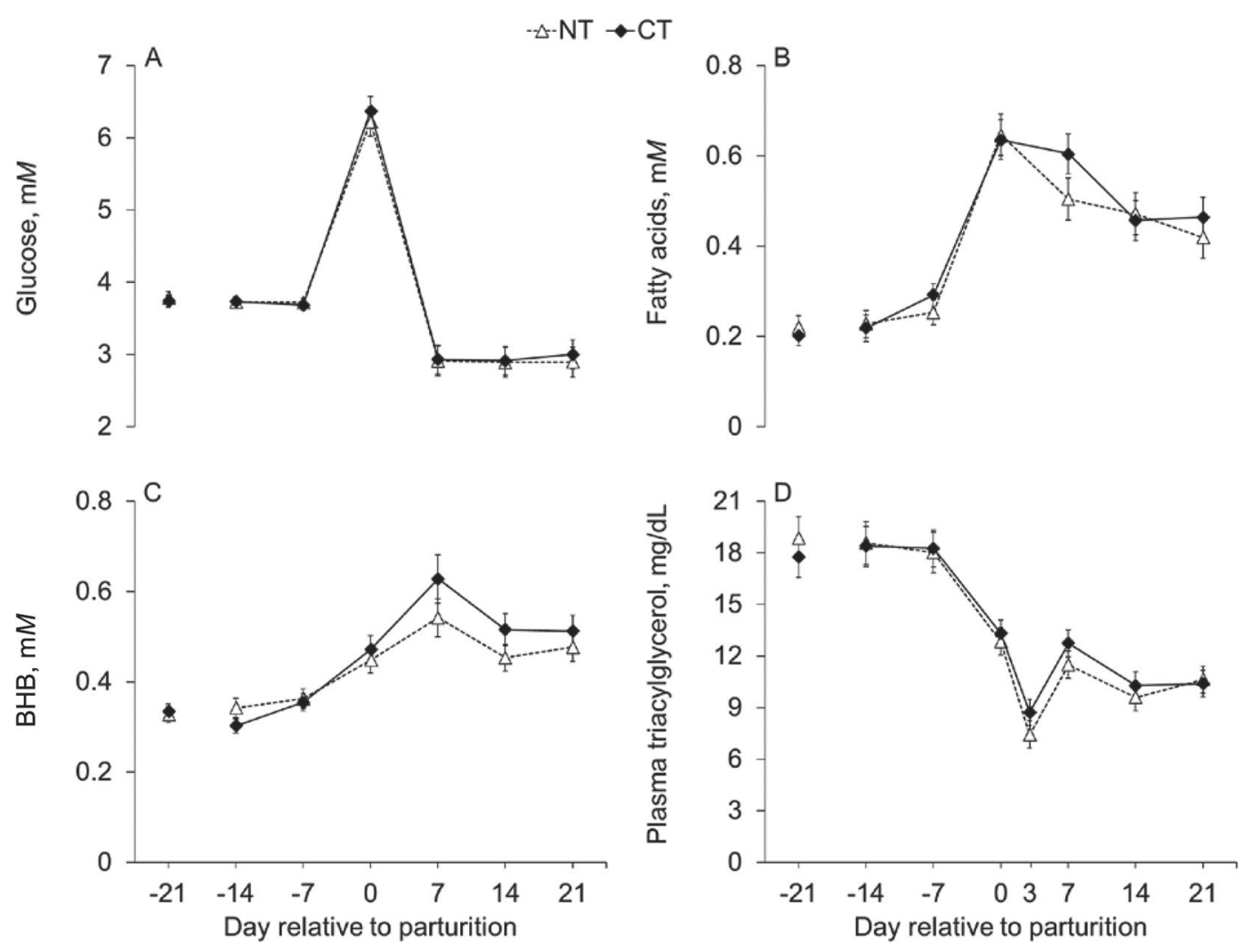

Figure 1. Concentrations of glucose (A), fatty acids (B), BHB (C), and triacylglycerol (D) in plasma of Holstein cows supplemented from $21 \mathrm{~d}$ pre- to $21 \mathrm{~d}$ postpartum with either $0(\Delta, \mathrm{NT})$ or $12.9 \mathrm{~g} / \mathrm{d}$ of choline ion $(\diamond, \mathrm{CT})$ as rumen-protected choline. Panel A, prepartum: effects of treatment $(P=0.76)$ and interaction between treatment and day $(P=0.56)$; postpartum: effects of treatment $(P=0.56)$ and interaction between treatment and day $(P=0.97)$. Panel $\mathrm{B}$, prepartum: effects of treatment $(P=0.54)$ and interaction between treatment and day $(P=$ $0.21)$; postpartum: effects of treatment $(P=0.37)$ and interaction between treatment and day $(P=0.15)$. Panel $\mathrm{C}$, prepartum: effects of treatment $(P=0.17)$ and interaction between treatment and day $(P=0.14)$; postpartum: effects of treatment $(P=0.09)$ and interaction between treatment and day $(P=0.77)$. Panel D, prepartum: effects of treatment $(P=0.99)$ and interaction between treatment and day $(P=0.73)$; postpartum: effects of treatment $(P=0.09)$ and interaction between treatment and day $(P=0.65)$. Error bars represent SEM.

\section{Prepartum Plasma Concentrations of Metabolites and Inflammatory Markers}

Supplementation with RPC during the last 3 wk of gestation did not affect the plasma concentrations of fatty acids, BHB, glucose, triacylglycerols (Figure 1), and urea $\mathrm{N}$ (Table 1). Likewise, treatment did not affect the concentrations of acute-phase proteins, fibrinogen, and haptoglobin (Figure 2; Table 1).

\section{Postpartum Plasma Concentrations of Metabolites and Inflammatory Markers}

Supplementing RPC did not affect postpartum concentrations of glucose or fatty acids (Table 2). Concentration of glucose (Figure 1A) sharply increased (day, $P<0.001$ ) on the day of calving to $6.3 \mathrm{mM}$ and then declined to $2.9 \mathrm{~m} M$ by $7 \mathrm{~d}$ postpartum after which it remained somewhat constant until $21 \mathrm{~d}$ postpartum.
Likewise, plasma concentration of fatty acids increased as cows approached parturition (Figure 1B) and then decreased (day, $P=0.001$ ) postpartum. Cows fed CT tended $(P=0.09)$ to have greater concentrations of BHB in the first $21 \mathrm{~d}$ postpartum than those fed NT (Figure $1 \mathrm{C})$. In addition, CT cows tended $(P=0.09)$ to have greater concentration of plasma triacylglycerol than cows fed NT during the first $21 \mathrm{~d}$ postpartum (Figure 1D). Supplementation with RPC did not affect concentrations of plasma urea N.

Treatment did not affect concentrations of fibrinogen, haptoglobin, and TNFo and they all increased in the postpartum period (Figure 2). Likewise, rectal temperature was not affected by supplementation with RPC (Figure 2D), and treatment did not affect the incidence of fever in the first $12 \mathrm{~d}$ postpartum (Table 3 ) or the daily prevalence of fever (NT $=28.6$ vs. CT $=29.8 \% ; P=0.87$; and treatment $\times$ day interaction, $P=0.97)$. 
Table 1. Prepartum concentrations of metabolites and inflammatory markers in plasma of cows supplemented with either 0 (NT) or $12.9 \mathrm{~g} / \mathrm{d}$ of choline ion (CT) as rumen-protected choline during the transition period

\begin{tabular}{|c|c|c|c|c|c|c|}
\hline \multirow[b]{2}{*}{ Item $^{1}$} & \multicolumn{2}{|c|}{ Treatment } & \multirow[b]{2}{*}{ SEM } & \multicolumn{3}{|c|}{$P$-value ${ }^{2}$} \\
\hline & NT & $\mathrm{CT}$ & & TRT & Day & TRT $\times$ day \\
\hline Fatty acids, $\mathrm{m} M$ & 0.240 & 0.255 & 0.027 & 0.54 & 0.01 & 0.21 \\
\hline $\mathrm{BHB},{ }^{3} \mathrm{~m} M$ & 0.352 & 0.326 & 0.020 & 0.17 & 0.01 & 0.14 \\
\hline Triacylglycerol, mg/dL & 18.30 & 18.32 & 1.10 & 0.99 & 0.58 & 0.73 \\
\hline Urea N, mg/dL & 9.19 & 9.33 & 0.30 & 0.71 & 0.48 & 0.65 \\
\hline
\end{tabular}

${ }^{1}$ Analyzed in samples collected on $\mathrm{d}-14$ and -7 relative to parturition.

${ }^{2} \mathrm{TRT}=$ effect of treatment $(\mathrm{NT}$ vs. $\mathrm{CT})$; day $=$ effect of day prepartum; TRT $\times$ day $=$ interaction between TRT and day.

${ }^{3}$ The BHB was transformed to the reciprocal $(1 / y)$, and fibrinogen and haptoglobin to the logarithm for statistical analyses, and the LSM and respective SEM were back transformed according to Jørgensen and Pedersen (1998) for data presentation.

${ }^{4} \mathrm{OD}=$ optical density.

\section{Postpartum Plasma Concentrations of Liposoluble Vitamins and Total Calcium}

Treatment did not affect the concentrations of $\alpha$-tocopherol, retinol, or calcidiol in plasma in the first
$7 \mathrm{~d}$ postpartum; however, cows fed CT had less $(P=$ $0.02)$ plasma concentration of $\beta$-carotene than cows fed NT (Figure 3; Table 4). Treatment did not affect the mean concentrations of tCa in plasma in the first 3 d postpartum (Figure 4A). Nevertheless, cows fed CT
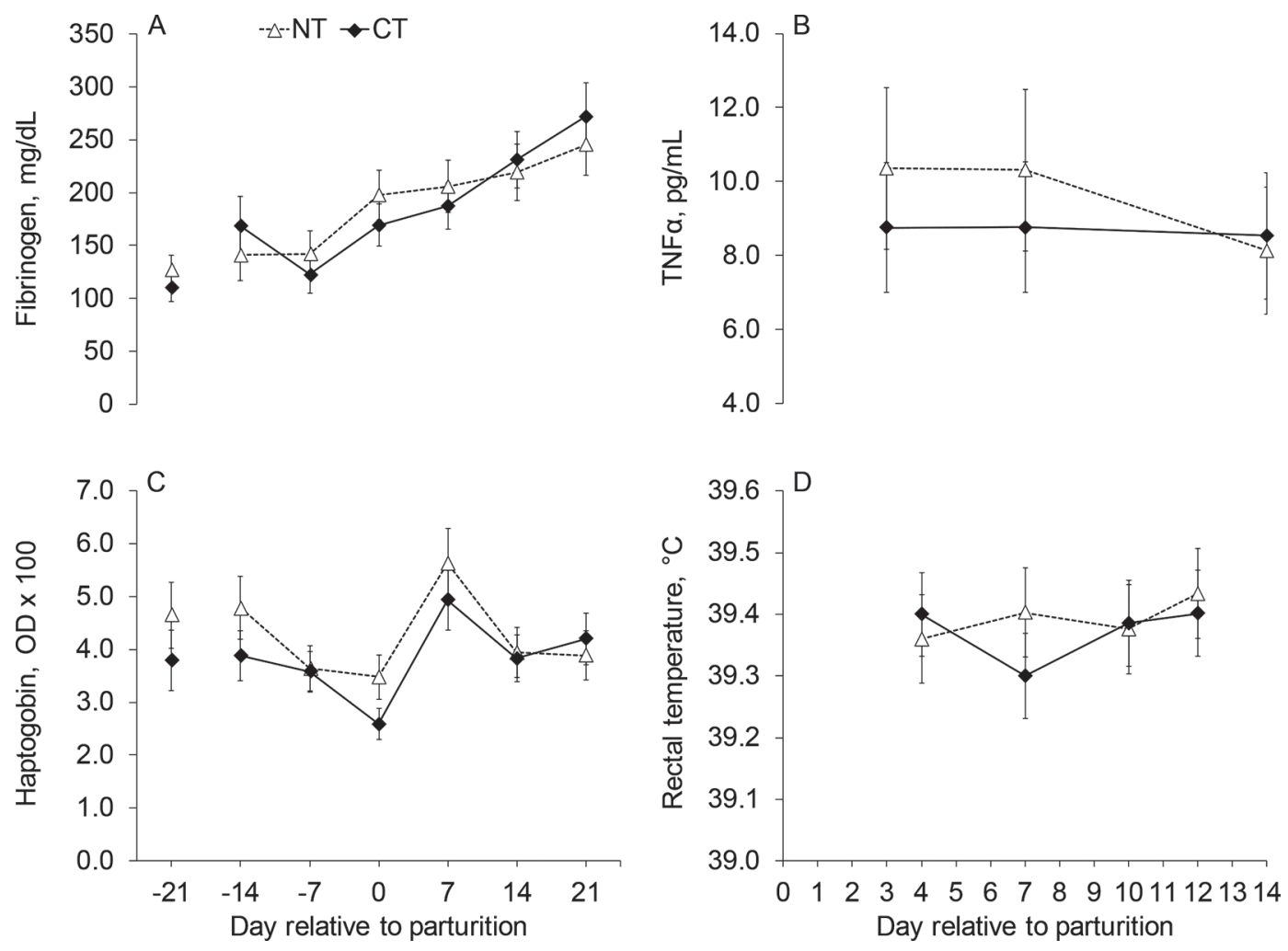

Figure 2. Concentrations of fibrinogen (A), tumor necrosis factor- $\alpha$ (TNF $\alpha$; B), haptoglobin (C; expressed as optical density, OD) in plasma, and rectal temperature (D) of Holstein cows supplemented from $21 \mathrm{~d}$ pre- to $21 \mathrm{~d}$ postpartum with either $0(\Delta, \mathrm{NT})$ or $12.9 \mathrm{~g} / \mathrm{d}$ of choline ion $(\diamond, \mathrm{CT})$ as rumen-protected choline. Panel A, prepartum: effects of treatment $(P=0.90)$ and interaction between treatment and day $(P=0.16)$; postpartum: effects of treatment $(P=0.80)$ and interaction between treatment and day $(P=0.49)$. Panel B: effects of treatment $(P=0.56)$ and interaction between treatment and day $(P=0.30)$. Panel $\mathrm{C}$, prepartum: effects of treatment $(P=0.23)$ and interaction between treatment and day $(P=0.20)$; postpartum: effects of treatment $(P=0.25)$ and interaction between treatment and day $(P=0.19)$. Panel D: effects of treatment $(P=0.72)$ and interaction between treatment and day $(P=0.43)$. Error bars represent SEM. 
Table 2. Postpartum concentrations of metabolites and inflammatory markers in plasma, and rectal temperature of cows supplemented with either $0(\mathrm{NT})$ or $12.9 \mathrm{~g} / \mathrm{d}$ of choline ion $(\mathrm{CT})$ as rumen-protected choline during the transition period

\begin{tabular}{|c|c|c|c|c|c|c|}
\hline \multirow[b]{2}{*}{ Item } & \multicolumn{2}{|c|}{ Treatment } & \multirow[b]{2}{*}{ SEM } & \multicolumn{3}{|c|}{$P$-value ${ }^{1}$} \\
\hline & NT & $\mathrm{CT}$ & & TRT & Day & TRT $\times$ day \\
\hline Fatty acids, ${ }^{2} \mathrm{~m} M$ & 0.511 & 0.540 & 0.036 & 0.37 & 0.001 & 0.15 \\
\hline $\mathrm{BHB}^{2,3} \mathrm{~m} M$ & 0.477 & 0.526 & 0.030 & 0.09 & 0.001 & 0.77 \\
\hline Triacylglycerol, ${ }^{4} \mathrm{mg} / \mathrm{dL}$ & 10.40 & 11.09 & 0.59 & 0.09 & 0.001 & 0.65 \\
\hline Urea $\mathrm{N}^{2}{ }^{2} \mathrm{mg} / \mathrm{dL}$ & 7.41 & 7.57 & 0.33 & 0.59 & 0.001 & 0.92 \\
\hline $\mathrm{TNF} \alpha,{ }^{3,6} \mathrm{pg} / \mathrm{mL}$ & 9.53 & 8.69 & 1.83 & 0.56 & 0.16 & 0.30 \\
\hline Rectal temperature, ${ }^{7}{ }^{\circ} \mathrm{C}$ & 39.39 & 39.37 & 0.06 & 0.72 & 0.61 & 0.43 \\
\hline
\end{tabular}

${ }^{1} \mathrm{TRT}=$ effect of treatment $(\mathrm{NT}$ vs. CT); day $=$ effect of day postpartum; TRT $\times$ day $=$ interaction between TRT and day.

${ }^{2}$ Analyzed in samples collected on d 0, 7, 14, and 21 postpartum.

${ }^{3}$ The BHB was transformed to the reciprocal $(1 / \mathrm{y})$, and fibrinogen, haptoglobin, and tumor necrosis factor $\alpha$ (TNF $\left.\alpha\right)$ to the logarithm for statistical analyses, and the LSM and respective SEM were back transformed according to Jørgensen and Pedersen (1998) for data presentation.

${ }^{4}$ Analyzed in samples collected on d 0,3, 7, 14, and 21 postpartum.

${ }^{5} \mathrm{OD}=$ optical density.

${ }^{6}$ Analyzed in samples collected on d 3, 7, and 14 postpartum.

${ }^{7}$ Rectal temperature measured on d 4, 7, 10, and 12 postpartum.

tended $(P=0.07)$ to have less incidence of subclinical hypocalcemia (Table 3 ), mostly because of an interaction $(P=0.09)$ between treatment and day postpartum. The prevalence of subclinical hypocalcemia was less $(P=0.04)$ in $\mathrm{CT}$ than $\mathrm{NT}$ on day of calving (NT $=40.3$ vs. $\mathrm{CT}=12.4 \%)$ and tended $(P=0.06)$ to be less for $\mathrm{CT}$ than $\mathrm{NT}$ on d 2 postpartum (3.4 vs. $0.6 \%$; Figure 4B).

\section{Postpartum Hepatic Concentrations of Triacylglycerol}

The concentration of hepatic triacylglycerol was the greatest on d 14 postpartum $(12.1 \pm 1.0 \%$ of tissue DM; day, $P<0.001)$ compared with $\mathrm{d} 7$ and 21 postpartum. Cows fed CT had a greater $(P<0.05)$ concentration of hepatic triacylglycerol than those fed NT

Table 3. Effect of supplementing diets of transition cows with rumen-protected choline on risk of diseases in Holstein cows in the first $21 \mathrm{~d}$ postpartum

\begin{tabular}{lccc}
\hline & \multicolumn{2}{c}{ Treatment $^{1}$} & \\
\cline { 2 - 3 } Item & $\mathrm{NT}$ & $\mathrm{CT}$ & P-value \\
\cline { 2 - 3 } Twins & $5.5(3 / 55)$ & $12.1(7 / 58)$ & 0.44 \\
Clinical disease & & & \\
Milk fever & $1.8(1 / 55)$ & $3.4(2 / 58)$ & 0.77 \\
Retained fetal membranes & $12.7(7 / 55)$ & $17.2(10 / 58)$ & 0.93 \\
Metritis & $10.9(6 / 55)$ & $17.2(10 / 58)$ & 0.62 \\
Puerperal metritis & $7.4(4 / 54)$ & $7.3(4 / 55)$ & 0.48 \\
Displaced abomasum & $3.6(2 / 55)$ & $1.7(1 / 58)$ & 0.39 \\
Mastitis & $5.5(3 / 55)$ & $5.2(3 / 58)$ & 0.97 \\
Respiratory & $1.8(1 / 55)$ & $1.7(1 / 58)$ & 0.99 \\
Morbidity & $25.5(14 / 55)$ & $34.5(20 / 58)$ & 0.55 \\
Multiple diseases & $9.1(5 / 55)$ & $10.3(6 / 58)$ & 0.86 \\
Hyperketonuria $_{\text {Fever }}$ & $18.2(10 / 55)$ & $22.4(13 / 58)$ & 0.49 \\
Endometritis $_{\text {Subclinical disease }}$ & $52.7(29 / 55)$ & $63.8(37 / 58)$ & 0.52 \\
Hypocalcemia $^{2}$ & $32.7(16 / 49)$ & $28.0(14 / 50)$ & 0.55 \\
Hyperketonemia $^{3}$ & & & \\
\hline
\end{tabular}

${ }^{1}$ Supplementation from $21 \mathrm{~d}$ pre- to $21 \mathrm{~d}$ postpartum with either 0 (NT) or $12.9 \mathrm{~g} / \mathrm{d}$ of choline ion $(\mathrm{CT})$ as rumen-protected choline.

${ }^{2}$ Reinhardt et al. (2011). Based on at least 1 blood sample with total $\mathrm{Ca}<2.0 \mathrm{mM}$ on d 0, 1, 2, or 3 postpartum. ${ }^{3} \mathrm{McArt}$ et al. (2011). Based on at least 1 blood sample with blood sample with BHB $>1.20 \mathrm{~m} M$ on d 0, 7, 14, and 21 postpartum. 

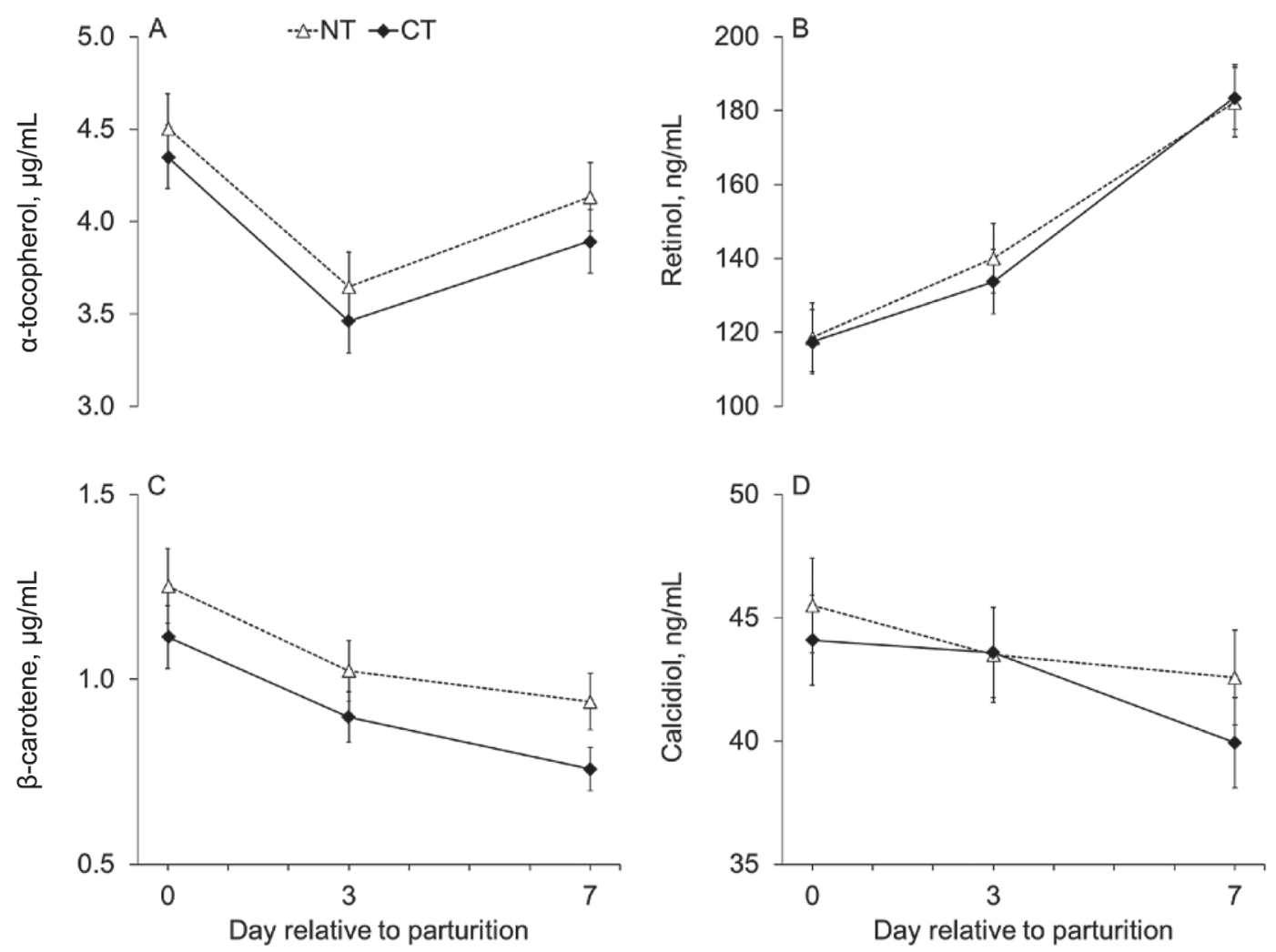

Figure 3. Concentrations of liposoluble vitamins: $\alpha$-tocopherol (A), retinol (B), $\beta$-carotene (C), and calcidiol (D; 25-hydroxycholecalciferol) in plasma of Holstein cows supplemented from $21 \mathrm{~d}$ pre- to $21 \mathrm{~d}$ postpartum with either $0(\Delta, \mathrm{NT})$ or $12.9 \mathrm{~g} / \mathrm{d}$ of choline ion $(\downarrow$, CT) as rumenprotected choline. Panel A: effects of treatment $(P=0.25)$ and interaction between treatment and day $(P=0.91)$. Panel B: effects of treatment $(P=0.81)$ and interaction between treatment and day $(P=0.65)$. Panel C: effects of treatment $(P=0.02)$ and interaction between treatment and day $(P=0.11)$. Panel D: effects of treatment $(P=0.37)$ and interaction between treatment and day $(P=0.23)$. Error bars represent SEM.

(Figure 5A), resulting in an increase of 2.5 percentage units of triacylglycerol expressed on tissue DM (Table $5)$. Consequently, cows fed CT had greater $(P=0.04)$ prevalence of fatty liver in the first $21 \mathrm{~d}$ postpartum (Figure 5B), resulting in a tendency $(P=0.10)$ for a greater proportion of cows of cows diagnosed with fatty liver at least once in the first $21 \mathrm{~d}$ postpartum (Table $5)$.

\section{Postpartum Diseases}

Treatment did not affect the incidence of postpartum diseases (Table 3). Furthermore, despite the tendency for greater concentration of BHB in CT than NT cows, the incidence of cows with hyperketonuria or hyperketonemia did not differ between treatments (Table 3 ); however, the daily prevalence of hyperketonemia

Table 4. Postpartum concentrations of liposoluble vitamins and total Ca in plasma of cows supplemented with either 0 (NT) or $12.9 \mathrm{~g} / \mathrm{d}$ of choline ion (CT) as rumen-protected choline (RPC) during the transition period

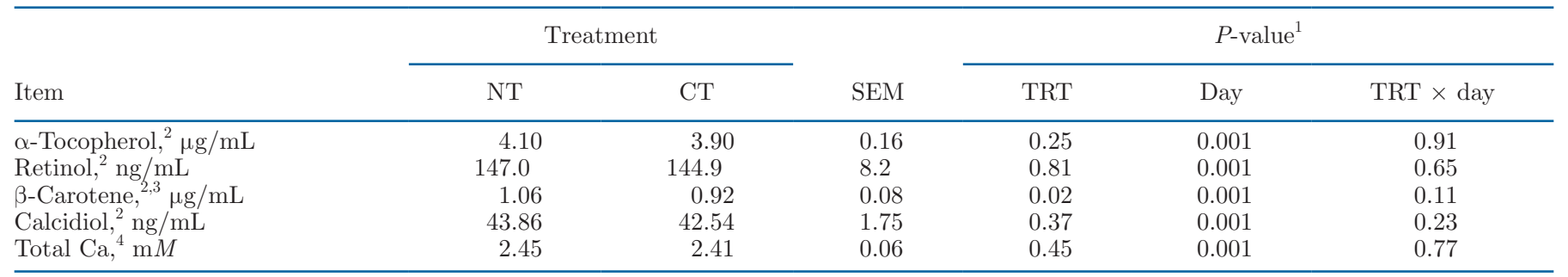

${ }^{1}$ TRT $=$ effect of treatment $(\mathrm{NT}$ vs. $\mathrm{CT}$ ); day $=$ effect of day postpartum; TRT $\times$ day $=$ interaction between TRT and day.

${ }^{2}$ Analyzed in samples collected on d 0,3 , and 7 postpartum.

${ }^{3} \beta$-Carotene was transformed to the logarithm for statistical analyses, and the LSM and respective SEM were back transformed according to Jørgensen and Pedersen (1998).

${ }^{4}$ Analyzed in samples collected on d 0, 1, 2, and 3 postpartum. 

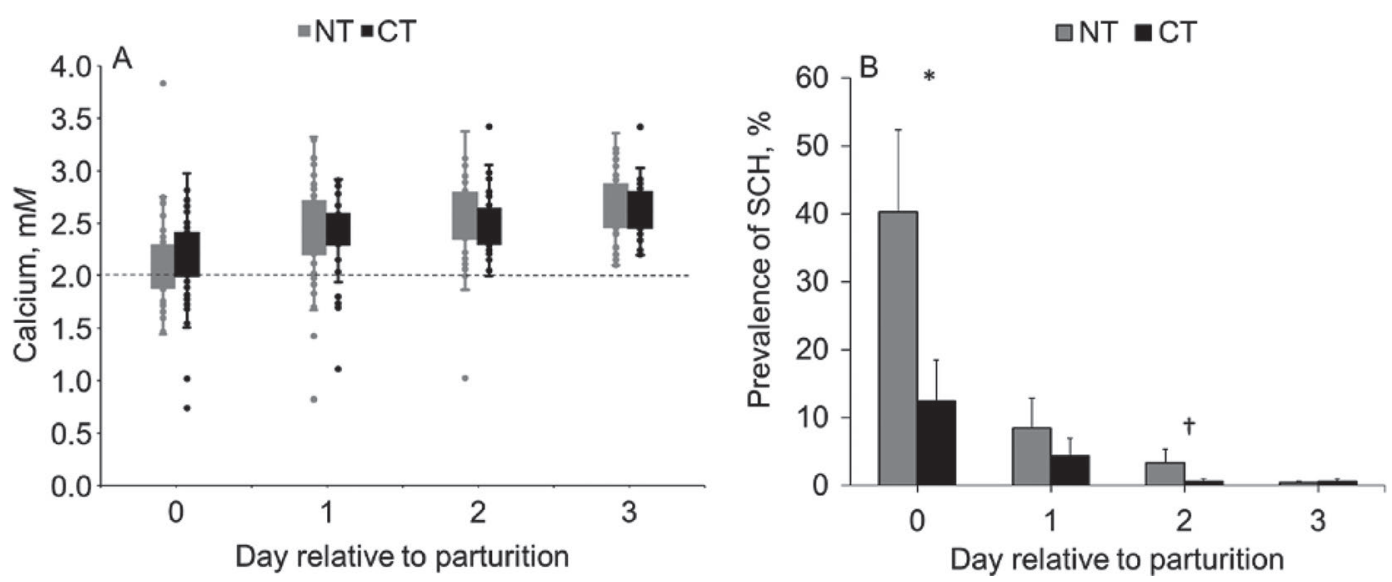

Figure 4. Concentrations of total $\mathrm{Ca}(\mathrm{A})$ and prevalence of subclinical hypocalcemia (B; $\mathrm{SCH}=$ total Ca $<2.0 \mathrm{~m} M$; Reinhardt et al., 2011) in plasma of Holstein cows supplemented from $21 \mathrm{~d}$ pre- to $21 \mathrm{~d}$ postpartum with either 0 (gray, NT) or $12.9 \mathrm{~g} / \mathrm{d}$ of choline ion (black, CT) as rumen-protected choline. Panel A: effects of treatment $(P=0.45)$ and interaction between treatment and day $(P=0.77)$. Panel B: effect of interaction between treatment and day $(P=0.09)$ for prevalence of SCH. At each day relative to parturition, differences between treatments were found: ${ }^{*} P \leq 0.05$, and $\dagger 0.05<P \leq 0.10$. Error bars represent SEM.

tended $(P=0.08)$ to increase in CT compared with NT cows (7.4 vs. $15.1 \%)$ because of a tendency $(P=$ $0.10)$ for an interaction between treatment and day. On d 7 postpartum, cows fed CT had greater $(P=0.01)$ prevalence hyperketonemia than those fed NT $(\mathrm{NT}=$ 6.1 vs. $\mathrm{CT}=18.8 \%$ ).

Morbidity in the first $21 \mathrm{~d}$ postpartum affected $30.1 \%$ of the cows, and $15.9 \%$ of the cows were diagnosed with more than 1 clinical disease. Treatment did not affect morbidity or incidence of multiple diseases for the first 21 d postpartum (Table 3 ).

\section{DISCUSSION}

Most diseases that affect dairy cows are first diagnosed in the first weeks of lactation and, to a large extent, diseases occur because of inadequate nutrient intake and dysregulated immune response associated with increased inflammation. Choline is an essential nutrient and has been shown to attenuate triacylglycerol infiltration into the liver (Zenobi et al., 2018b) and inflammatory responses (Zenobi et al., 2017). It was hypothesized that supplementing $12.9 \mathrm{~g} / \mathrm{d}$ of choline ion as RPC to cows during the transition period would improve metabolic status and reduce measures of inflammatory response postpartum. Nevertheless, supplementing RPC to transition dairy cows had no effects on concentrations of blood metabolites or markers of inflammatory responses postpartum. Furthermore, supplementing RPC during the transition period did not affect the risk of diseases in early lactation, except for a reduction in subclinical hypocalcemia, but increased prevalence of hyperketonemia and fatty liver.

Table 5. Effect of supplementing diets of transition cows with rumen-protected choline (RPC) on concentrations of hepatic triacylglycerol and risk of fatty liver in Holstein cows postpartum

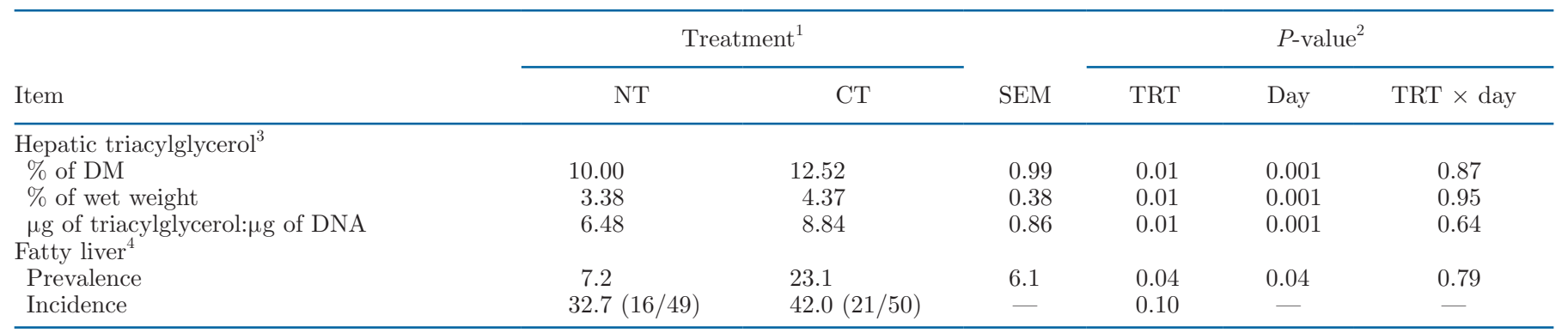

${ }^{1}$ Supplementation from $21 \mathrm{~d}$ pre- to $21 \mathrm{~d}$ postpartum with either 0 (NT) or $12.9 \mathrm{~g} / \mathrm{d}$ of choline ion (CT) as RPC.

${ }^{2} \mathrm{TRT}=$ effect of treatment (NT vs. CT); day $=$ effect of day postpartum; TRT $\times$ day $=$ interaction between TRT and day.

${ }^{3}$ Liver collected for biopsy on d 7, 14, and 21 postpartum.

${ }^{4}$ Gaal et al. (1983). Based on at least 1 liver sample with liver triacylglycerol $>5 \%$ on a wet basis on d 7, 14, or 21 postpartum. The prevalence was evaluated weekly from 7 to $21 \mathrm{~d}$ postpartum. 

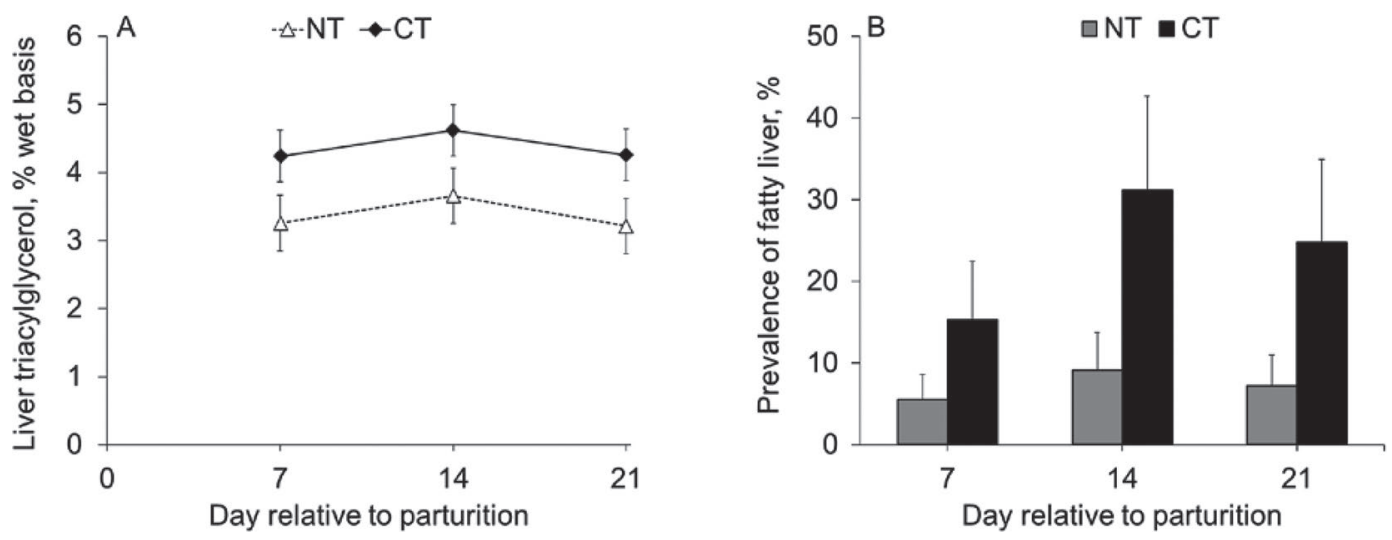

Figure 5. Concentrations of liver triacylglycerol (A) and prevalence of fatty liver (B; $>5 \%$ triacylglycerol wet basis; Gaal et al., 1983) in Holstein cows supplemented from $21 \mathrm{~d}$ pre- to $21 \mathrm{~d}$ postpartum with either 0 ( $\Delta$ or gray bars, NT) or $12.9 \mathrm{~g} / \mathrm{d}$ of choline ion $(\checkmark$ or black bars, CT) as rumen-protected choline. Panel A: effects of treatment $(P=0.01)$ and interaction between treatment and day $(P=0.95)$. Panel B: effects of treatment $(P=0.04)$ and interaction between treatment and day $(P=0.79)$. Error bars represent SEM.

Lipotropic effects of choline in enhancing lipid export from the liver and preventing triacylglycerol accumulation have been widely documented in the literature (Yao and Vance, 1988; Chandler and White, 2017), and in dairy cows, choline is thought to reduce the risk of fatty liver because supplementation with RPC reduces triacylglycerol accumulation in the hepatic tissue (Cooke et al., 2007; Zenobi et al., 2018b). Surprisingly, contrary to our initial hypothesis, CT cows had greater content of triacylglycerol in the liver and tended to have greater plasma BHB concentrations in the first $21 \mathrm{~d}$ postpartum than NT cows. Consequently, CT cows had greater prevalence of fatty liver. In spite of the changes in hepatic triacylglycerol content, the concentrations of inflammatory markers in plasma postpartum were unaffected by treatment. In many species, the rate of very-low density lipoprotein export is strongly related to the rate of hepatic phosphatidylcholine synthesis (Cole et al., 2012), and dairy cows affected by fatty liver during the transition period display smaller concentrations of phosphatidylcholine and sphingomyelins in plasma than cows without fatty liver (Imhasly et al., 2014). Plasma concentrations of most choline-related phospholipids decreases at the end of gestation until calving and then progressively increases as the lactation progresses in dairy cows (Artegoitia et al., 2014; Imhasly et al., 2015). Zenobi et al. (2018b) demonstrated that increasing the amounts of choline ion from 0 to $25.8 \mathrm{~g} / \mathrm{d}$ as RPC reduced the concentration of liver triacylglycerol and plasma haptoglobin in a linear fashion in dry Holstein cows in negative nutrient balance. Perhaps the $12.9 \mathrm{~g} / \mathrm{d}$ was insufficient to reduce hepatic triacylglycerol accumulation postpartum in light of the increased yield of ECM with no corresponding increase in DMI (Bollatti et al., 2020).
Arshad et al. (2020) identified 8 experiments in which cows were supplemented or not with RPC and postpartum hepatic triacylglycerol concentration was reported. They showed no effect of supplementing RPC during the transition period on hepatic triacylglycerol (Arshad et al., 2020). Similar to the present experiment, supplementing RPC increased yield ECM. The conflicting results between the reduction in hepatic triacylglycerol in dry cows (Cooke et al., 2007; Zenobi et al., 2018b) and those of the present experiment or reported by Arshad et al. (2020) might be related to the effect of choline stimulating milk yield, which can affect nutrient balance. Triacylglycerol accumulation in hepatic tissue is associated with net energy balance (Bobe et al., 2004), and cows in $\mathrm{CT}$ had more negative energy balance in the first $21 \mathrm{~d}$ postpartum compared with cows fed NT. Therefore, it is possible that the lipotropic effects of choline might have been overshadowed by the improved efficiency of ECM yield per kilogram of DMI resulting in more negative net energy balance in the first $21 \mathrm{~d}$ postpartum. To understand the link between treatment, hepatic triacylglycerol, and energy balance, an additional statistical analysis was performed for hepatic triacylglycerol including the mean net energy balance in the first $21 \mathrm{~d}$ postpartum in the model. Energy balance was negatively related to hepatic triacylglycerol content $(\beta=-0.23 ; \mathrm{SE}=0.03)$ supporting the concept that cows in more negative energy balance had greater hepatic triacylglycerol; however, the effect of treatment remained significant, although the magnitude of difference between treatments was reduced by half. These results suggest that the differences in hepatic triacylglycerol between treatments were in part explained by the differences in net energy balance, and the fact that cows fed CT had smaller net energy balance postpar- 
tum (Bollatti et al., 2020) might have negated a reduction in hepatic triacylglycerol by RPC. It is suggested that the increase in hepatic triacylglycerol in cows fed $\mathrm{RPC}$ is the result of improved lactation performance not followed by changes in DMI, which resulted in more negative energy balance. Experiments with lactating cows in which RPC increased production and reduced hepatic triacylglycerol also observed an increase in DMI (Santos and Lima, 2009; Zom et al., 2011).

Cows in CT tended to have a greater plasma concentration of BHB in the first $21 \mathrm{~d}$ postpartum, although incidence of hyperketonemia and ketonuria did not differ between NT and CT cows. Because cows fed CT tended to be in more negative net energy balance in the first $21 \mathrm{~d}$ postpartum (Bollatti et al., 2020), it is expected that hepatic ketogenesis might be enhanced. Also, supplementing choline to dairy cows usually increases tissue content of carnitine (Coleman et al., 2019), and carnitine facilitates the transport of fatty acids into the mitochondria for $\beta$-oxidation and, consequently, might increase disposal of hepatic lipids through synthesis of ketones (Bremer, 1983). The increased concentrations of BHB were not accompanied by an increased prevalence of cows with concentrations above the threshold considered critical for postpartum health (McArt et al., 2011), and cows fed CT were more productive than those fed NT; thus, it is suggested that the increased concentrations of BHB were a consequence of enhanced disposal of hepatic fatty acids. Beta-hydroxybutyric acid can be used as an energy source by multiple tissues or as precursor for synthesis of milk fat in the mammary gland. Others have reported greater postpartum BHB concentrations accompanied with a positive carryover effect on yields of ECM in early lactation dairy cows (Albornoz and Allen, 2018). Establishment of critical thresholds for plasma BHB were based on epidemiological studies (McArt et al., 2011), but designed experiments showed that induced hyperketonemia by continuous i.v. infusion of BHB to values of $1.74 \mathrm{mM}$ did not result in negative effects on intake or milk yield in dairy cows (Zarrin et al., 2013).

Some researchers have suggested that abrupt changes in DMI around parturition can alter the gastrointestinal barrier in dairy cows (Kvidera et al., 2017), and supplementing choline may enhance integrity of enterocytes and absorption of nutrients by either repairing a damaged protective barrier in the small intestine or improving synthesis of chylomicrons (Zenobi et al., 2018b). We found that RPC supplementation tended to increase plasma concentration of triacylglycerols in plasma in the first $21 \mathrm{~d}$ postpartum, and RPC decreased the incidence of subclinical hypocalcemia by $3 \mathrm{~d}$ postpartum compared with NT. It is possible that these responses might be related to the effects of choline on intestinal integrity (Takahashi et al., 1982). At this point, it is interesting to note that this is the second experiment that has detected changes in incidence of subclinical hypocalcemia in dairy cows (Zenobi et al., 2018a).

Contrary to our initial hypothesis, supplementing choline to transition dairy cows did not influence concentrations of $\alpha$-tocopherol, retinol, and calcidiol in plasma of dairy cows in the first week postpartum. In fact, $\beta$-carotene concentration was less in plasma of $\mathrm{CT}$ compared with that of NT cows. Choline supplementation as RPC has been reported to increase plasma concentration of $\alpha$-tocopherol in some experiments with transition cows (Pinotti et al., 2003; Sun et al., 2016). On the other hand, Coleman et al. (2019) demonstrated that the infusion of choline chloride into the abomasum of mid-lactation Holsteins cows in negative nutrient balance did not affect the concentrations of $\alpha$-tocopherol, retinol, and $\beta$-carotene in plasma. Therefore, the effect of choline on the absorption and metabolism of liposoluble vitamins does not seem to be a consistent response and warrants further investigation.

Collectively, the improvements in performance observed by Bollatti et al. (2020) do not seem to have been mediated by a reduction in hepatic triacylglycerol, incidence of clinical diseases, or reduced signs of inflammation based on the findings of the present manuscript. In the companion manuscript (Bollatti et al., 2020), the authors discussed a potential role of choline stimulating mammary cell proliferation; briefly, choline and its derivative molecules might play roles in mammary cells by stimulating cell proliferation (Ramírez de Molina et al., 2004). Therefore, it is possible that supplemental choline as RPC might benefit cows in late gestation and early lactation when concentrations of choline metabolites are lowest and mammary cell accretion remains active.

\section{CONCLUSIONS}

Supplementing $12.9 \mathrm{~g} / \mathrm{d}$ choline ion in a rumen-protected form as a top-dress to parous Holstein cows from $21 \mathrm{~d}$ pre- to $21 \mathrm{~d}$ postpartum resulted in greater hepatic triacylglycerol content and plasma BHB concentration in the first $21 \mathrm{~d}$ postpartum, but concentrations of inflammatory markers and liposoluble vitamins in plasma were unaffected. Treatment did not affect incidence of clinical diseases; however, RPC increased the concentration of plasma triacylglycerol, but reduced the incidence of subclinical hypocalcemia. It is suggested that the increase in hepatic triacylglycerol in cows fed $\mathrm{RPC}$ is partly mediated by the improvements in lactation performance not followed by concurrent changes in DMI, which resulted in more negative energy balance. Based on the current findings, the improvements in lac- 
tation performance and feed efficiency observed in the companion manuscript with supplementing $12.9 \mathrm{~g} / \mathrm{d}$ of choline ion cannot be explained by reduced fatty liver or improved peripartum health or inflammatory status. Other mechanisms are suggested and they might be related to potential effects of choline on mammary epithelial cell proliferation or enhanced uptake of nutrients.

\section{ACKNOWLEDGMENTS}

The authors thank Gaston Alfaro, Juan Ignacio Racca, Juan Fernando Zelaya, and Norberto Gallino (University of Florida) for their help to ensure proper daily care of cows and collection of samples, and Sergei Sennikov (University of Florida) for help with laboratory assays. We thank Laman K. Mamedova and Barry J. Bradford from Kansas State University and Robin da Silva from the University of Florida for their collaborations on laboratory assays. The experiment was partially supported by a grant from Balchem Animal Nutrition and Health (New Hampton, NY).

\section{REFERENCES}

Albornoz, R. I., and M. S. Allen. 2018. Highly fermentable starch at different diet starch concentrations decreased feed intake and milk yield of cows in the early postpartum period. J. Dairy Sci. 101:8902-8915.

Arshad, U., M. G. Zenobi, C. R. Staples, and J. E. P. Santos. 2020. Meta-analysis of the effects of supplemental rumen-protected choline during the transition period on performance and health of parous dairy cow. J. Dairy Sci. 103:282-301. https://doi.org/10 .3168/jds.2019-16842.

Artegoitia, V. M., J. L. Middleton, F. M. Harte, S. R. Campagna, and M. J. De Veth. 2014. Choline and choline metabolite patterns and associations in blood and milk during lactation in dairy cows. PLoS One 9:e103412.

Bell, A. W. 1995. Regulation of organic nutrient metabolism during transition from late pregnancy to early lactation. J. Anim. Sci. 73:2804-2819.

Bertics, S. J., R. R. Grummer, C. Cadorniga-Valino, and E. E. Stoddard. 1992. Effect of prepartum dry matter intake on liver triglyceride concentration and early lactation. J. Dairy Sci. 75:1914-1922.

Blanco, D., M. P. Fernández, and M. D. Gutiérrez. 2000. Simultaneous determination of fat-soluble vitamins and provitamins in dairy products by liquid chromatography with a narrow-bore column. Analyst 125:427-431.

Bobe, G., J. W. Young, and D. C. Beitz. 2004. Invited review: Pathology, etiology, prevention, and treatment of fatty liver in dairy cows. J. Dairy Sci. 87:3105-3124.

Bollatti, J. M., M. G. Zenobi, N. A. Artusso, G. F. Alfaro, A. M. Lopez, B. A. Barton, C. R. Staples, and J. E. P. Santos. 2020. Timing of initiation and duration of feeding rumen-protected choline affects performance of lactating Holstein cows. J. Dairy Sci. 103:4174-4191. https://doi.org/10.3168/jds.2019-17293.

Box, G., and D. Cox. 1964. An analysis of transformations. J. Royal Stat. Soc. B (Methodological) 26:211-252.

Bradford, B. J., L. K. Mamedova, J. E. Minton, J. S. Drouillard, and B. J. Johnson. 2009. Daily Injection of tumor necrosis factor- $\alpha$ increases hepatic triglycerides and alters transcript abundance of metabolic genes in lactating dairy cattle. J. Nutr. 139:1451-1456.
Bremer, J. 1983. Carnitine - Metabolism and functions. Physiol. Rev. 63:1420-1480.

Chandler, T. L., and H. M. White. 2017. Choline and methionine differentially alter methyl carbon metabolism in bovine neonatal hepatocytes. PLoS One 12:e0171080.

Cole, L. K., J. E. Vance, and D. E. Vance. 2012. Phosphatidylcholine biosynthesis and lipoprotein metabolism. Biochim. Biophys. Acta 1821:754-761.

Coleman, D. N., A. Alharthi, V. Lopreiato, E. Trevisi, M. Miura, Y.X. Pan, and J. J. Loor. 2019. Choline supply during negative nutrient balance alters hepatic cystathionine $\beta$-synthase, intermediates of the methionine cycle and transsulfuration pathway, and liver function in Holstein cows. J. Dairy Sci. 102:8319-8331. https://doi .org/10.3168/jds.2019-16406.

Combs, G. F., Jr. 2012. The Vitamins. Elsevier Science \& Technology. ProQuest Ebook Central. https://ebookcentral.proquest.com/lib/ ufl/detail.action?docID $=872576$.

Cooke, R. F., N. S. Del Río, D. Z. Caraviello, S. J. Bertics, M. H. Ramos, and R. R. Grummer. 2007. Supplemental choline for prevention and alleviation of fatty liver in dairy cattle. J. Dairy Sci 90:2413-2418

Drackley, J. K. 1999. Biology of dairy cows during the transition period: The final frontier? J. Dairy Sci. 82:2259-2273.

Elek, P., T. Gaál, and F. Husvéth. 2013. Influence of rumen-protected choline on liver composition and blood variables indicating energy balance in periparturient dairy cows. Acta Vet. Hung. 61:59-70.

Erdman, R. A., R. D. Shaver, and J. H. Vandersall. 1984. Dietary choline for the lactating cow: Possible effects on milk fat synthesis. J. Dairy Sci. 67:410-415.

Farney, J. K., L. K. Mamedova, B. H. Godsey, and B. J. Bradford. 2011. Technical note: Validation of an ELISA for measurement of tumor necrosis factor alpha in bovine plasma. J. Dairy Sci. 94:3504-3509.

Folch, J., M. Lees, and G. H. Sloane Stanley. 1957. A simple method for the isolation and purification of total lipids from animal tissues. J. Biol. Chem. 226:497-509.

Foster, L. B., and R. T. Dunn. 1973. Stable reagents for determination of serum triglycerides by a colorimetric Hantzsch condensation method. Clin. Chem. 19:338-340.

Gaal, T., I. M. Reid, R. A. Collins, C. J. Roberts, and B. V. Pike. 1983. Comparison of biochemical and histological methods of estimating fat content of liver of dairy cows. Res. Vet. Sci. 34:245-248.

Gochman, N., and J. M. Schmitz. 1972. Application of a new peroxide indicator reaction to the specific automated determination of glucose with glucose oxidase. Clin. Chem. 18:943-950.

Imhasly, S., C. Bieli, H. Naegeli, L. Nyström, M. Ruetten, and C. Gerspach. 2015. Blood plasma lipidome profile of dairy cows during the transition period. BMC Vet. Res. 11:252.

Imhasly, S., H. Naegeli, S. Baumann, M. von Bergen, A. Luch, H. Jungnickel, S. Potratz, and C. Gerspach. 2014. Metabolomic biomarkers correlating with hepatic lipidosis in dairy cows. BMC Vet. Res. 10:122.

Johnson, M. M., and J. P. Peters. 1993. Technical note: An improved method to quantify nonesterified fatty acids in bovine plasma. J. Anim. Sci. 71:753-756.

Jørgensen, E., and A. R. Pedersen. 1998. How to obtain those nasty standard errors from transformed data-And why they should not be used. Biometry Res. Unit Int. Rep. 7. Danish Inst. Agric. Sci. $1-20$.

Kvidera, S. K., M. J. Dickson, M. Abuajamieh, D. B. Snider, M. V. S. Fernandez, J. S. Johnson, A. F. Keating, P. J. Gorden, H. B. Green, K. M. Schoenberg, and L. H. Baumgard. 2017. Intentionally induced intestinal barrier dysfunction causes inflammation, affects metabolism, and reduces productivity in lactating Holstein cows. J. Dairy Sci. 100:4113-4127.

Labarca, C., and K. Paigen. 1980. A simple, rapid, and sensitive DNA assay procedure. Anal. Biochem. 102:344-352.

Lima, F. S., R. S. Bisinotto, E. S. Ribeiro, L. F. Greco, H. Ayres, M. G. Favoreto, M. R. Carvalho, K. N. Galvão, and J. E. P. Santos. 2013. Effects of 1 or 2 treatments with prostaglandin $\mathrm{F}_{2 \alpha}$ on sub- 
clinical endometritis and fertility in lactating dairy cows inseminated by timed artificial insemination. J. Dairy Sci. 96:6480-6488.

Makimura, S., and N. Suzuki. 1982. Quantitative determination of bovine serum haptoglobin and its elevation in some inflammatory diseases. Nihon juigaku zasshi. Jpn. J. Vet. Sci. 44:15-21.

Marsh, W. H., B. Fingerhut, and H. Miller. 1965. Automated and manual direct methods for the determination of blood urea. Clin. Chem. 11:624-627.

McArt, J. A. A., D. V. Nydam, P. A. Ospina, and G. R. Oetzel. 2011. A field trial on the effect of propylene glycol on milk yield and resolution of ketosis in fresh cows diagnosed with subclinical ketosis. J. Dairy Sci. 94:6011-6020.

Nelson, C. D., J. D. Lippolis, T. A. Reinhardt, R. E. Sacco, J. L. Powell, M. E. Drewnoski, M. O'Neil, D. C. Beitz, and W. P. Weiss. 2016. Vitamin D status of dairy cattle: Outcomes of current practices in the dairy industry. J. Dairy Sci. 99:10150-10160.

Piepenbrink, M. S., and T. R. Overton. 2003. Liver metabolism and production of cows fed increasing amounts of rumen-protected choline during the periparturient period. J. Dairy Sci. 86:1722-1733.

Pinotti, L., A. Baldi, I. Politis, R. Rebucci, L. Sangalli, and V. Dell'Orto. 2003. Rumen-protected choline administration to transition cows: Effects on milk production and vitamin E status. J. Vet. Med. A Physiol. Pathol. Clin. Med. 50:18-21.

Ramírez de Molina, A. R., M. Báñez-Coronel, R. Gutiérrez, A. Rodríguez-González, D. Olmeda, D. Megías, and J. C. Lacal. 2004. Choline kinase activation is a critical requirement for the proliferation of primary human mammary epithelial cells and breast tumor progression. Cancer Res. 64:6732-6739.

Reinhardt, T. A., J. D. Lippolis, B. J. McCluskey, J. P. Goff, and R. L. Horst. 2011. Prevalence of subclinical hypocalcemia in dairy herds. Vet. J. 188:122-124.

Ribeiro, E. S., G. Gomes, L. F. Greco, R. L. A. Cerri, A. Vieira-Neto, P. L. J. Monteiro Jr., F. S. Lima, R. S. Bisinotto, W. W. Thatcher, and J. E. P. Santos. 2016. Carryover effect of postpartum inflammatory diseases on developmental biology and fertility in lactating dairy cows. J. Dairy Sci. 99:2201-2220.

Rodney, R. M., N. Martinez, E. Block, L. L. Hernandez, P. Celi, C. D. Nelson, J. E. P. Santos, and I. J. Lean. 2018. Effects of prepartum dietary cation-anion difference and source of vitamin D in dairy cows: Vitamin D, mineral, and bone metabolism. J. Dairy Sci. 101:2519-2543.

Santos, J. E. P., and F. S. Lima. 2009. Feeding rumen-protected choline to transition dairy cows. Pages 149-159 in Proc. 20th Ann. Florida Ruminant Nutr. Symp. Univ. Florida, Gainesville.

Sharma, B. K., and R. A. Erdman. 1988. Effects of high amounts of dietary choline supplementation on duodenal choline flow and production responses of dairy cows. J. Dairy Sci. 71:2670-2676.

Sun, F., Y. Cao, C. Cai, S. Li, C. Yu, and J. Yao. 2016. Regulation of nutritional metabolism in transition dairy cows: Energy homeosta- sis and health in response to post-ruminal choline and methionine. PLoS One 11:e0160659. https://doi.org/10.1371/journal.pone .0160659 .

Takahashi, Y., T. Mizunuma, and Y. Kishino. 1982. Ultracytochemical studies on fat absorption by choline-deficient rats. Acta Histochem. Cytochem. 15:90-101.

Yao, Z. M., and D. E. Vance. 1988. The active synthesis of phosphatidylcholine is required for very low density lipoprotein secretion from rat hepatocyte. J. Biol. Chem. 263:2998-3004.

Zahra, L. C., T. F. Duffield, K. E. Leslie, T. R. Overton, D. Putnam, and S. J. LeBlanc. 2006. Effect of rumen-protected choline and monensin on milk production and metabolism of peri-parturient dairy cows. J. Dairy Sci. 89:4808-4818.

Zarrin, M., L. De Matteis, M. C. M. B. Vernay, O. Wellnitz, H. A. van Dorland, and R. M. Bruckmaier. 2013. Long-term elevation of $\beta$-hydroxybutyrate in dairy cows through infusion: Effects on feed intake, milk production, and metabolism. J. Dairy Sci. 96:29602972.

Zenobi, M. G., R. Gardinal, J. E. Zuniga, A. L. G. Dias, C. D. Nelson, J. P. Driver, B. A. Barton, J. E. P. Santos, and C. R. Staples. 2018a. Effects of supplementation with ruminally protected choline on performance of multiparous Holstein cows did not depend upon prepartum caloric intake. J. Dairy Sci. 101:1088-1110.

Zenobi, M. G., A. M. Lopez, J. E. Zuniga, C. D. Nelson, J. P. Driver, K. C. Jeong, R. A. Mir, B. A. Barton, J. E. P. Santos, and C. R. Staples. 2017. Prepartum energy intake and supplementation of rumen-protected choline (RPC) influence biomarkers of the immune system of lactating dairy cows. J. Dairy Sci. 100(Suppl. 2):407 (Abstr.).

Zenobi, M. G., T. L. Scheffler, J. E. Zuniga, M. B. Poindexter, S. R. Campagna, H. F. Castro Gonzalez, A. T. Farmer, B. A. Barton, J. E. P. Santos, and C. R. Staples. 2018b. Feeding increasing amounts of ruminally protected choline decreased fatty liver in nonlactating, pregnant Holstein cows in negative energy status. J. Dairy Sci. 101:5902-5923.

Zom, R. L., J. Van Baal, R. M. A. Goselink, M. J. de Veth, and A. M. van Vuuren. 2011. Effect of rumen-protected choline on performance and hepatic triacylglycerol concentrations in early-lactating dairy cattle. J. Dairy Sci. 94:4016-4027.

\section{ORCIDS}

C. D. Nelson (ํ https://orcid.org/0000-0003-0195-5610

C. R. Staples @ https://orcid.org/0000-0002-0237-946X

J. E. P. Santos $\odot$ https://orcid.org/0000-0003-3403-1465 